\title{
Persistent Discrimination of TB in Southeastern China: Results from Four Repeated Population- Based Surveys During the Period of 2006-2018
}

\author{
Xinyi Chen ${ }^{1, *}$ \\ Wei Wangl,* \\ Qianhui Hua 2 ** \\ Hong $\mathrm{Xu}^{3}$ \\ Fei Wang' \\ Kui Liu (iD) \\ Ying Peng' \\ Bin Chen iD ' \\ Jianmin Jiang ${ }^{1,4}$ \\ 'Department of Tuberculosis Control \\ and Prevention, Zhejiang Provincial \\ Center for Disease Control and \\ Prevention, Hangzhou, People's Republic \\ of China; ${ }^{2}$ School of Medicine, Ningbo \\ University, Ningbo, People's Republic of \\ China; ${ }^{3}$ Department of Tuberculosis \\ Control and Prevention, Xiaoshan \\ District Center for Disease Control and \\ Prevention, Hangzhou, People's Republic \\ of China; ${ }^{4}$ Key Laboratory of Vaccine, \\ Prevention and Control of Infectious \\ Disease of Zhejiang Province, Hangzhou, \\ People's Republic of China
}

*These authors contributed equally to this work
Correspondence: Bin Chen; Jianmin Jiang $\mathrm{Tel} / \mathrm{Fax}+86-57 \mathrm{I}-87$ II -5 I83

Email bchen@cdc.zj.cn; jmjiang@cdc.zj.cn
Objective: To analyze the changes in discriminatory attitudes and isolated behaviors of the public toward tuberculosis (TB) in the Zhejiang Province and to determine the associated factors with TB discrimination.

Methods: Data were obtained from four cross-sectional population-based investigations from 2006 to 2018. A total of 26,246 respondents were interviewed using unified questionnaires that measured knowledge, attitudes, and behaviors regarding TB. The changes in public attitudes and behaviors towards TB over time were analyzed. The effect of sociodemographic factors and the level of TB awareness on TB discriminatory attitudes and isolated behaviors were evaluated.

Results: The results of these four cross-sectional studies found that TB discrimination had not changed much over the decade. Overall, discriminatory attitudes were present in $63.5 \%$ of the respondents who knew about TB (81.2\%). Nearly $31.2 \%$ of those who reported being surrounded by people with TB $(5.8 \%)$ showed isolated behaviors. Older respondents, those with a low education level, and farmers were prone to having discriminatory attitudes or behaviors. Those aware of the infectiousness and transmission routes of $\mathrm{TB}$, and those who felt that TB was serious were more likely to discriminate against TB $(P<0.001)$. Those aware that $\mathrm{TB}$ can be cured were non-discriminatory ( $\mathrm{aOR}=0.77,95 \% \mathrm{CI}: 0.72-0.82)$.

Conclusion: Discriminatory attitudes and isolated behaviors toward TB have not changed significantly in southeastern China over the survey years, and persistent discrimination against TB still exists among the public. The multiple causes of discrimination cannot be addressed through basic health education. Tailor-made strategies, relevant policy measures, and an enabling social environment for TB are urgently required.

Keywords: tuberculosis, discrimination, attitude, behavior

\section{Introduction}

Tuberculosis (TB) is the leading cause of death from a single infectious agent. According to the World Health Organization (WHO), in 2019, there were more than 10 million new TB cases worldwide, 1.2 million people died from TB, and another 200,000 deaths resulted from TB among people living with human immunodeficiency virus (HIV). ${ }^{1}$ Presently, the only effective way to control TB is to diagnose and treat TB patients as quickly as possible. Although TB can be cured, patients need to complete a standard course of treatment for 6-8 months and visit health centres regularly, which together with the symptoms of TB (chronic cough, weight loss, and fatigue), make it difficult for patients to hide the fact that they have TB. ${ }^{2}$ 
Several studies have found that psychological health problems are common among patients with TB. ${ }^{3,4}$ This is because once identified, TB patients may suffer a discriminatory attitude of rejection and prejudice from the public or themselves due to their disease, leading to delays in diagnosis and treatment. ${ }^{5,6}$ This not only negatively affects the quality of life of the patients and their families, but also further hinders the effective control and prevention of TB.

Generally, discrimination occurs in two ways. Selfdiscrimination refers to a patient's sense of shame and stigma due to a particular route of infection of the disease. $^{7}$ Social discrimination occurs when the public intentionally denigrates or even harms patients for fear that their rights to health will be violated when they exercise their rights to equal treatment, and this discrimination and unequal treatment are exacerbated by the herd mentality of the public. $^{7}$

Self and social discrimination can reduce patient compliance with treatment and thus have a negative impact on the overall prevention of the disease. On the one hand, patients' internal fear of being discriminated against for having TB makes it easier for them to conceal their condition, delay access to medical services, and seek informal treatment, which may lead to more severe disease symptoms and the spread of TB to a larger number of healthy individuals. ${ }^{8,9}$ On the other hand, as a result of social discrimination, many TB patients are reluctant to continue with care or to be supervised by doctors, fearing that frequent visits will expose their illness, which directly affects doctors' management of patients and the implementation of TB treatment strategies, making follow-up and control of TB difficult. ${ }^{2}$

Previous studies have explored the factors associated with TB discrimination. Individual characteristics such as age, gender, and level of education were reported to have a significant association with the thoughts and attitudes of TB-related discrimination. ${ }^{10-12}$ Additionally, TB patients are vulnerable to discrimination due to incorrect knowledge or awareness about TB and misconceptions about the disease from the public. ${ }^{13}$ At the same time, persistent discrimination against TB reinforces the patients' internal stigma and, coupled with insufficient knowledge about TB, can easily lead to poor health-seeking behaviour and thus endanger their health. ${ }^{14}$ Lower levels of discrimination were reported in communities with a better understanding of TB, where healthcare workers were supportive and adequate patient support mechanisms were available. ${ }^{15}$ An appropriate or adequate understanding of TB is also expected to address other psychosocial effects of $\mathrm{TB}$ and positively change any existing discriminatory attitudes. ${ }^{16}$

Zhejiang is a representative province in southeastern China. The incidence of TB is relatively low in Zhejiang Province, with a reported incidence rate of 45.3/100,000 in 2018, and is constantly declining. ${ }^{17}$ However, due to an increasingly mobile population and the challenges associated with drug-resistant TB, the Zhejiang Province still faces a high TB burden. From 2006-2018, the Zhejiang Province conducted four cross-sectional surveys to comprehensively understand the knowledge, attitudes, and behaviors of its citizens about TB, establishing a baseline of TB awareness among the general public in the province, and providing direction and focus for more effective TB health promotional efforts. However, to the best of our knowledge, no study to date has attempted to understand the change in public attitudes and behaviors related to $\mathrm{TB}$, which negatively affects the assessment of TB health education and promotional efforts.

Therefore, based on these four surveys, this study aimed to analyze the changes in potential discriminatory attitudes and isolated behaviors of the public toward TB in the Zhejiang Province, and to analyze the association between different characteristics of the respondents with discriminatory attitudes and behaviors. These findings would help provide scientific recommendations for the formulation of health education programs to create a more supportive atmosphere for TB patients.

\section{Methods \\ Study Setting and Population}

Zhejiang, a southeast province with 11 prefectures and 90 counties, is one of the most densely populated and welldeveloped provinces in China. In 2019, Zhejiang had a population of 58.5 million people and the per capita gross domestic product (GPD) was 107,624 RMB. ${ }^{18}$

Since 2006, the Zhejiang Province initiated the first population-based survey on public knowledge, attitudes, and practices regarding TB. So far, the Zhejiang Province has conducted four surveys in 2006, 2010, 2014, and 2018, with a total of over 25,000 participants.

\section{Study Design, Data Collection and Quality Assurance}

The data for the current study were obtained from four repeated cross-sectional population-based investigations. 
The sample size required for each study is calculated using the following formula:

$$
n=\frac{p(1-p)}{\left(\frac{d}{z_{\alpha}}\right)^{2}}
$$

where $\mathrm{n}$ means the required sample size. In this formula, $\alpha$ refers to the significance level and $d$ is the allowable error, and they are assumed as 0.05 and 0.04 respectively, $50 \%$ is regarded as the expected proportion of participants in the study districts that had good knowledge about TB and is represented in the formula by $p$. A non-response rate of $10 \%$ is also considered. In each survey, a multistage stratified cluster sampling method was applied (Figure 1). The survey covered 10 prefectures in 2006 (no survey was conducted in the prefecture of Zhoushan because of its small population in that year, while the last three surveys took into account geographical factors, so Zhoushan was also included in the survey), compared with all 11 prefectures in 2010, 2014, and 2018. Firstly, 11 prefectures in Zhejiang Province (10 prefectures in year 2006) were stratified into five categories according to their level of economic development. Eleven counties (10 counties in year 2006) were then randomly selected to ensure that there was at least one sample county from each prefecture and 2 3 counties from each socioeconomical level. Secondly, based on the results of the first stage of sampling, two townships were randomly selected in

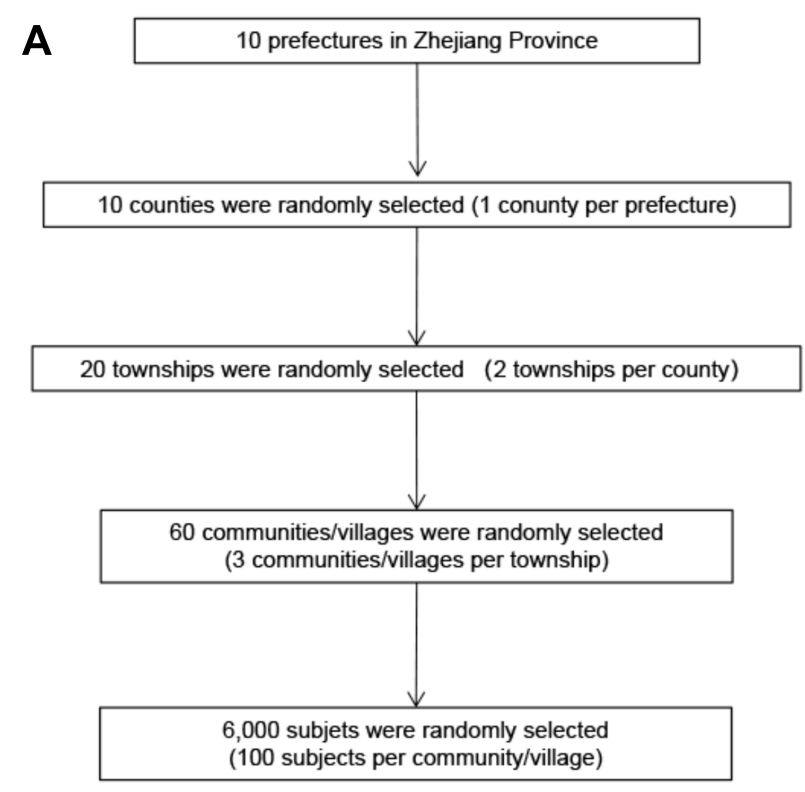

each of the selected counties. Thirdly, three communities or villages from each township were randomly selected. Finally, based on the results of the third stage of sampling, 100 households per community or village were selected using a systematic random sampling technique. Therefore, the required sample size was 6000 in 2006 and 6600 in the other years.

Individuals aged between 12 75 years (including 12 and 75 years) were eligible for recruitment. The eligible subjects were required to meet the following inclusion criteria: 1) Zhejiang residents, who had a local household registration and resided in the Zhejiang Province during the survey, or had a foreign registered residence but had lived in the Zhejiang Province for more than 6 months; 2) had no communication disorders or mental illnesses; and 3) provided written informed consent (eligible individuals who were under the age of 18 were required to obtain the written consent of their guardians). After the four stages of sampling, a face-to-face interview was conducted by trained investigators using a unified questionnaire, which included information about socio-demographic characteristics (sex, age, place of residence, education, marital status, health insurance, family income in the past year, family numbers, etc.), knowledge (some options were fine-tuned in the subsequent surveys according to the updated TB knowledge), attitudes, and behaviors toward TB. The content of the

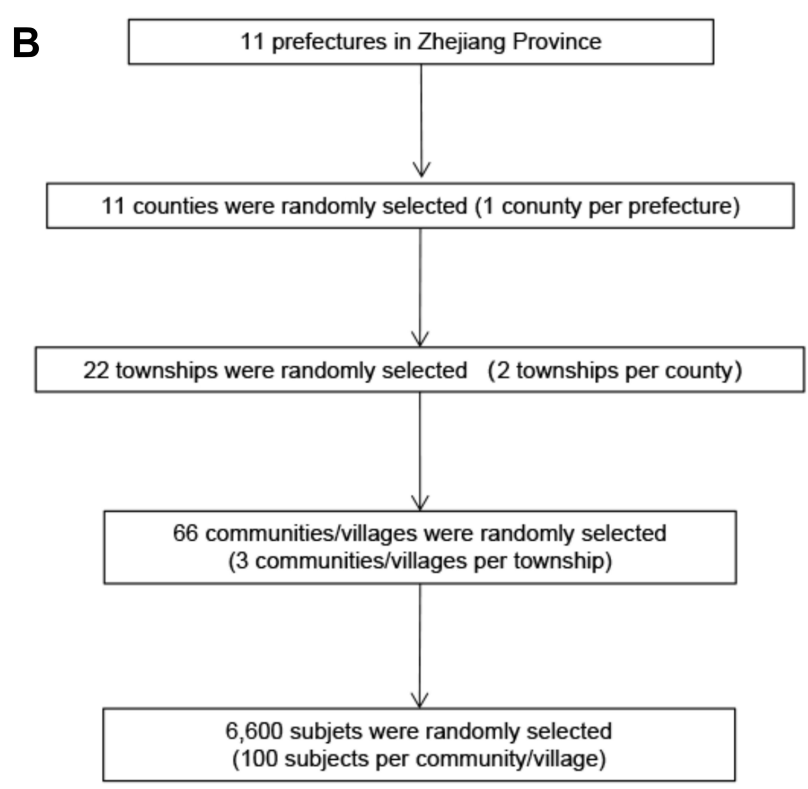

Figure I (A) The multistage stratified cluster sampling process of the 2006 survey in Zhejiang Province, China. (B) The multistage stratified cluster sampling process of the 2010, 2014 and 2018 surveys in Zhejiang Province, China. 
questionnaire is based on the national survey protocol, and takes into account the questions in the national TB awareness survey, as well as Zhejiang Province's local situation.

The data from the questionnaires were double-entered by professionals for logic error detection and collation. The local Centre for Disease Control and Prevention (CDC) staff at each investigation site received provincial training and were responsible for the interviews and collection of questionnaires. The final datasets from the four surveys were centrally established by the unified provincial database for quality verification.

\section{Operational Definition of Terms Knowledge Regarding TB}

Five core pieces of TB knowledge items were selected from the questionnaire as the main variables and were divided into the categories of susceptibility and severity of the disease to determine the respondents' awareness of TB (Table 1). Public knowledge of TB susceptibility was defined by the responses to the following items: 1) TB is contagious; 2) TB can be transmitted by coughing and sneezing; and 3) TB should be suspected if a cough and expectoration persists for more than two weeks. The awareness of TB severity was reflected using two questions: 1) TB is curable; and 2) What do you think of the severity of TB?

\section{Discriminatory Attitudes and Isolated Behaviors}

A negative or unfair treatment toward an individual based on his/her health status was considered to be a discriminatory attitude and behavior. ${ }^{16}$ In our study, a hypothetical scenario (What would you do to the people around you if they had TB, see Table 2) was asked to the respondents, and there were four attitudes for them to choose, ie "not getting along with them anymore", "reducing contact with them", "contacting them as usual", and

Table I Classification of TB Knowledge

\begin{tabular}{|c|c|}
\hline Categories & Knowledge About TB \\
\hline \multirow[t]{3}{*}{ Susceptibility } & TB is contagious \\
\hline & TB can be transmitted by coughing and sneezing \\
\hline & $\begin{array}{l}\text { TB should be suspected if a cough and expectoration } \\
\text { persist for more than two weeks }\end{array}$ \\
\hline \multirow[t]{2}{*}{ Severity } & $\begin{array}{l}\text { If standard treatment is adhered to, most cases of TB } \\
\text { can be cured }\end{array}$ \\
\hline & What do you think of the severity of TB \\
\hline
\end{tabular}

"be more caring and considerate of them". For further analysis, two attitudes, "not getting along with them anymore" and "reducing contact with them" were considered as discriminatory attitudes, while attitudes of "contacting them as usual" and "be more caring and considerate of them" were classified as non-discriminatory.

With respect to respondents' behaviors, only those who had had TB patients around them were asked about the changes in their contact with these patients, with three options for respondents to choose from: "less contact than before"; "contacting them as usual"; and "more contact than before". For better distinction, the option of "less contact than before" was classified as isolated behavior, and the treatments of "contacting them as usual" and "more contact than before" were considered non-isolation.

\section{Statistical Analysis}

Data from the four surveys were collated using Microsoft Excel and options were combined after standardization. All statistical procedures were performed using the SPSS package for Windows, v24.0.0 (IBM Corporation, Armonk, NY, USA). Descriptive data are summarized and presented as frequencies and percentages The chi-square trend test was used to analyze changes in public attitudes and behaviors towards TB over time. Multivariate logistic regression was carried out to analyse the factors associated with public attitudes and behaviors that influence discrimination against TB. P-values were 2-tailed with statistical significance set at 0.05 .

\section{Results}

\section{Socio-Demographic Characteristics of the Study Respondents}

As shown in Table 3, a total of 26,246 respondents were included in the four KAP surveys of TB through the unified questionnaire, with a similar proportion of males $(49.6 \%)$ and females $(50.4 \%)$. The majority of the study respondents were aged between 50 59 years (28.3\%). Nearly $78.9 \%$ of the respondents resided in rural areas. More than half of the respondents had at least a secondary school education $(\mathrm{n}=14,524,55.3 \%)$. Most participants were married $(85.9 \%)$, and $54.1 \%$ were farmers. Nearly one-third of the respondents had three family members $(32.5 \%)$. The different characteristics of the respondents were statistically significant between the years. 
Table 2 Respondents' Attitudes and Behaviors Toward TB Across the Four Surveys from 2006 to 2018 in Zhejiang Province, China

\begin{tabular}{|l|c|c|c|c|c|}
\hline \multirow{2}{*}{ Items } & \multicolumn{3}{|c|}{ Year } \\
\cline { 2 - 5 } & 2006 & 2010 & 2014 & 2018 \\
\hline What would you do to the people around you if they had TB? & & & & \\
Not getting along with them anymore & $310(6.3)$ & $299(5.6)$ & $148(2.9)$ & $423(7.0)$ & $1180(5.5)$ \\
Reducing contact with them & $2921(59.3)$ & $3194(60.2)$ & $2705(53.3)$ & $3551(59.1)$ & $12,371(58.0)$ \\
Contacting them as usual & $1000(20.3)$ & $1113(21.0)$ & $1489(29.4)$ & $990(16.5)$ & $4592(21.5)$ \\
Be more caring and considerate of them & $697(14.1)$ & $704(13.3)$ & $730(14.4)$ & $1049(17.4)$ & $3180(14.9)$ \\
What did you do when you knew that people around you had TB? & & & & \\
Less contact than before & $103(26.7)$ & $89(36.3)$ & $87(25.8)$ & $195(35.3)$ & $474(31.2)$ \\
Contacting them as usual & $276(71.5)$ & $150(61.2)$ & $241(71.5)$ & $352(63.7)$ & $1019(67.0)$ \\
More contact than before & $7(1.8)$ & $6(2.4)$ & $9(2.7)$ & $6(1.1)$ & $28(1.8)$ \\
\hline
\end{tabular}

\section{Respondents' Awareness of TB Knowledge}

Overall, 21,322 (81.2\%) of the participants in the four surveys had heard of TB (Table 4). Nearly $87.6 \%$ of the respondents had knowledge of the infectiousness of TB, while the awareness of suspicious symptoms of TB was the weakest $(33.3 \%)$. With regard to the transmission mode of TB, a total of 15,640 (73.4\%) respondents knew that TB could be transmitted through coughing and sneezing. When asked about TB severity, only $7.9 \%$ of the respondents considered TB to be a non-serious disease, whereas $43.6 \%$ viewed it as very serious. Nearly twothirds of the people believe that TB can be cured (65.1\%).

\section{Respondents' Attitudes and Behaviors Toward TB}

Overall, discriminatory attitudes and behaviors were present in $63.5 \%$ and $31.2 \%$ of the respondents who had heard of TB, respectively. The public's discriminatory attitudes and isolated behaviors towards TB in different survey years and their changes were presented in Figure 2, which showed that although there was a downward trend in discriminatory attitudes towards $\mathrm{TB}$, the decline was slow, while discriminatory behaviors towards TB were on the rise. The trend test showed statistically significant differences in trend changes in public's discriminatory attitudes $(\mathrm{Z}=4.29, \quad P=0.038)$ and isolated behaviors ( $\mathrm{Z}=4.18, P=0.041)$ towards TB over the years.

The details of the four surveys on attitudes and behaviors are presented in Table 2. About $58.0 \%$ of respondents said they would reduce contact with people around them if they had TB. Less than $15 \%$ of the respondents felt that they would care more for TB patients. Regarding isolated behaviors, among those who answered that they had TB patients around them $(\mathrm{n}=1521,5.8 \%)$, nearly a third of them indicated that they were discriminatory $(\mathrm{n}=474,31.2 \%)$. Only $1.8 \%(\mathrm{n}=28)$ responded that they had increased their contact with TB patients around them.

\section{Factors Influencing Respondents' Attitudes Towards TB}

In a scenario where the people around you were infected with TB, age appeared to be a factor influencing public attitudes toward TB. Older individuals were more likely to exhibit discriminatory attitudes than younger individuals $(P<0.001)$. Conversely, the higher the level of education, the more non-discriminatory the attitudes were. Compared to the unemployed, government staff $(\mathrm{aOR}=0.79,95 \% \mathrm{CI}: 0.65-0.97)$, health care workers $(\mathrm{aOR}=0.53,95 \% \mathrm{CI}: 0.41-0.70)$, and industrial workers $(\mathrm{aOR}=0.79,95 \% \mathrm{CI}: 0.70-0.90)$ were more likely to show non-discriminatory attitudes toward TB patients. As for the effect of TB awareness on respondents' attitudes, the tendency to discriminate against TB was higher among those who believed that TB was more severe $(P<0.001)$, infectious $(\mathrm{aOR}=1.25,95 \% \mathrm{CI}: 1.12-1.39)$, and those who knew the transmission modes of TB (aOR $=2.08,95 \%$ CI: 1.91-2.25). However, nondiscriminatory attitudes were more pronounced among those who were aware of the suspected symptoms of TB $(\mathrm{aOR}=0.84,95 \% \mathrm{CI}: 0.79-0.90)$ and knew that it can be cured (aOR $=0.77,95 \%$ CI: 0.72-0.82) (Table 5).

\section{Factors Influencing Respondents' Behaviors Towards TB}

A multivariate regression analysis of TB alienation behaviors indicated that in the 2018 survey, people were more likely to show alienating behaviors toward TB patients around them 
Table 3 Socio-Demographic Characteristics of the Respondents Across the Four Surveys from 2006 to 2018 in Zhejiang Province, China

\begin{tabular}{|c|c|c|c|c|c|}
\hline \multirow[t]{2}{*}{ Characteristics } & \multicolumn{4}{|l|}{ Year $(n, \%)$} & \multirow[t]{2}{*}{ Total } \\
\hline & 2006 & 2010 & 2014 & 2018 & \\
\hline \multicolumn{6}{|l|}{ Sex } \\
\hline Male & $2945(49.1)$ & $3302(50.5)$ & $345 \mathrm{I}(52.8)$ & $3323(46.3)$ & $|3,02|(49.6)$ \\
\hline Female & $305 I(50.9)$ & $3237(49.5)$ & $3086(47.2)$ & $385 I(53.7)$ & $13,225(50.4)$ \\
\hline \multicolumn{6}{|l|}{ Age in years } \\
\hline $12 \sim 19$ & $195(3.3)$ & $147(2.2)$ & $234(3.6)$ & $287(4.0)$ & $863(3.3)$ \\
\hline $20 \sim 29$ & $594(9.9)$ & $646(9.9)$ & 467 (7.I) & $634(8.8)$ & $2341(8.9)$ \\
\hline $30 \sim 39$ & $1352(22.5)$ & $1084(16.6)$ & $930(14.2)$ & $1050(14.6)$ & $4416(16.8)$ \\
\hline $40 \sim 49$ & $1606(26.8)$ & 1957 (29.9) & $1772(27.1)$ & I $442(20.1)$ & $6777(25.8)$ \\
\hline $50 \sim 59$ & $1718(28.7)$ & I884 (28.8) & $2022(30.9)$ & $1808(25.2)$ & $7432(28.3)$ \\
\hline$\geq 60$ & $528(8.8)$ & $821(12.6)$ & $1105(16.9)$ & $1953(27.2)$ & $4407(16.8)$ \\
\hline \multicolumn{6}{|l|}{ Residence } \\
\hline Urban & $996(16.6)$ & $637(9.7)$ & $801(12.3)$ & $3097(43.2)$ & $5531(21.1)$ \\
\hline Rural & $5000(83.4)$ & $5902(90.3)$ & $5736(87.7)$ & $4077(56.8)$ & $20,715(78.9)$ \\
\hline \multicolumn{6}{|l|}{ Educational status } \\
\hline Illiterate & $1250(20.8)$ & $882(13.5)$ & $848(13.0)$ & $817(11.4)$ & $3797(14.5)$ \\
\hline Primary School & $1915(31.9)$ & $2190(33.5)$ & $2033(3 I . I)$ & $1786(24.9)$ & $7924(30.2)$ \\
\hline Secondary school ${ }^{a}$ & $1919(32.0)$ & $2328(35.6)$ & $2369(36.2)$ & $2328(32.5)$ & $8944(34.1)$ \\
\hline High school $^{b}$ & $676(11.3)$ & $784(12.0)$ & $829(12.7)$ & $999(13.9)$ & $3288(12.5)$ \\
\hline Junior college & $155(2.6)$ & $239(3.7)$ & $25 I(3.8)$ & $561(7.8)$ & $1206(4.6)$ \\
\hline University & $81(1.4)$ & $116(1.8)$ & $206(3.2)$ & $683(9.5)$ & $1086(4.1)$ \\
\hline \multicolumn{6}{|l|}{ Marital status } \\
\hline Married & $5128(85.5)$ & $566 \mid(86.6)$ & $5618(85.9)$ & $615 \mid(85.7)$ & $22,558(85.9)$ \\
\hline Unmarried & $635(10.6)$ & $630(9.6)$ & $617(9.4)$ & $691(9.6)$ & $2573(9.8)$ \\
\hline Divorced/Widowed/Others & $233(3.9)$ & $248(3.8)$ & $297(4.5)$ & $332(4.6)$ & $1110(4.2)$ \\
\hline \multicolumn{6}{|l|}{ Occupation } \\
\hline Government staff & $139(2.3)$ & $126(1.9)$ & $120(1.8)$ & $323(4.5)$ & $708(2.7)$ \\
\hline Health care workers & $4 \mathrm{I}(0.7)$ & $43(0.7)$ & $64(1.0)$ & $153(2.1)$ & $30 I(I . I)$ \\
\hline Teachers & $43(0.7)$ & $49(0.7)$ & $5 \mathrm{I}(0.8)$ & $223(3.1)$ & $367(1.4)$ \\
\hline Professional technicians & $248(4.1)$ & $308(4.7)$ & $312(4.8)$ & $585(8.2)$ & I453 (5.5) \\
\hline Business/Service personnel & $391(6.5)$ & $620(9.5)$ & $603(9.2)$ & $933(13.0)$ & $2547(9.7)$ \\
\hline Industrial workers & $661(11.0)$ & $718(11.0)$ & $920(14.1)$ & $960(13.4)$ & $3259(12.4)$ \\
\hline Farmers & $3845(64.1)$ & $396 \mid(60.6)$ & $3722(56.9)$ & $2679(37.3)$ & $14,207(54.1)$ \\
\hline Students & $307(5.1)$ & $240(3.7)$ & $252(3.9)$ & $320(4.5)$ & $1118(4.3)$ \\
\hline Unemployed & $321(5.4)$ & $474(7.2)$ & $492(7.5)$ & $998(13.9)$ & $2285(8.7)$ \\
\hline \multicolumn{6}{|l|}{ Number of households } \\
\hline 1 & $302(5.0)$ & $300(4.6)$ & $242(3.7)$ & $360(5.0)$ & $1204(4.6)$ \\
\hline 2 & $|35|(22.5)$ & $1244(19.0)$ & $999(15.3)$ & $1534(21.4)$ & $5128(19.5)$ \\
\hline 3 & $2182(36.4)$ & $2065(31.6)$ & $2109(32.3)$ & $2187(30.5)$ & $8543(32.5)$ \\
\hline 4 & $1375(22.9)$ & 1466 (22.4) & $1369(20.9)$ & $1482(20.7)$ & $5692(21.7)$ \\
\hline$\geq 5$ & $786(13.1)$ & 1464 (22.4) & $1815(27.8)$ & $1611(22.5)$ & $5676(21.6)$ \\
\hline
\end{tabular}

Notes: ${ }^{a}$ Secondary school: years 13-15. 'High school: years 16-18.

than in 2006 (aOR $=1.77,95 \%$ CI: $1.21-2.58)$. Farmers exhibited stronger isolated behaviors compared with the jobless $(\mathrm{aOR}=2.43,95 \%$ CI: $1.49-3.95)$, while the differences between other occupations and unemployment were not statistically significant. Respondents who were aware of the infectiousness of TB $(\mathrm{aOR}=1.87,95 \% \mathrm{CI}$ : 
Table 4 Awareness About Susceptibility and Severity of TB Among the Respondents Across the Four Surveys from 2006 to 2018 in Zhejiang Province, China

\begin{tabular}{|c|c|c|c|c|c|}
\hline Knowledge About TB & 2006 & 2010 & 2014 & 2018 & Total \\
\hline \multicolumn{6}{|l|}{ Heard of TB } \\
\hline Yes & $4928(82.2)$ & $5309(81.2)$ & $5072(77.6)$ & $6013(83.8)$ & $21,322(8 \mid .2)$ \\
\hline No & $1068(17.8)$ & $1230(18.8)$ & $1465(22.4)$ & $1161(16.2)$ & $4924(18.8)$ \\
\hline \multicolumn{6}{|l|}{$\mathrm{TB}$ is contagious } \\
\hline Yes & $4307(87.4)$ & $4684(88.2)$ & $4261(84.1)$ & $5422(90.2)$ & $18,674(87.6)$ \\
\hline No/Unknown & $621(12.6)$ & $625(11.8)$ & $808(15.9)$ & $591(9.8)$ & $2645(12.4)$ \\
\hline \multicolumn{6}{|c|}{ TB can be transmitted by coughing and sneezing } \\
\hline Yes & $3311(67.2)$ & $3833(72.2)$ & 3639 (7I.7) & $4857(80.8)$ & $15,640(73.4)$ \\
\hline No/Unknown & $1617(32.8)$ & I 476 (27.8) & $1433(28.3)$ & $1156(19.2)$ & $5682(26.6)$ \\
\hline \multicolumn{6}{|c|}{ TB should be suspected if a cough and expectoration persist for more than two weeks } \\
\hline Yes & $763(15.5)$ & $2176(41.0)$ & $2000(39.4)$ & $2168(36.1)$ & $7107(33.3)$ \\
\hline No/Unknown & $4164(84.5)$ & $3134(59.0)$ & $3070(60.6)$ & $3845(63.9)$ & $14,213(66.7)$ \\
\hline \multicolumn{6}{|c|}{ If standard treatment is adhered to, most cases of TB can be cured } \\
\hline Yes & $2989(60.7)$ & $3386(63.8)$ & $2788(55.0)$ & $4708(78.3)$ & $|3,87|(65.1)$ \\
\hline No/Unknown & $1939(39.3)$ & $1923(36.2)$ & $2284(45.0)$ & $1305(2 \mid .7)$ & 7451 (34.9) \\
\hline \multicolumn{6}{|c|}{ What do you think of the severity of TB } \\
\hline Low & $319(6.5)$ & $458(8.6)$ & $646(12.7)$ & $253(4.2)$ & 1676 (7.9) \\
\hline Normal & $2092(42.5)$ & 2638 (49.7) & 3009 (59.3) & $2620(43.6)$ & $10,359(48.6)$ \\
\hline High & 2517 (5I.I) & $2213(41.7)$ & 1417 (27.9) & $3140(52.2)$ & 9287 (43.6) \\
\hline
\end{tabular}

$1.01-3.46)$ and suspected symptoms $(\mathrm{aOR}=1.62,95 \% \mathrm{CI}$ : $1.20-2.18$ ) were more likely to be discriminating than those who were not (Table 6).

\section{Discussion}

Comparing the results of the four surveys on public attitudes and behaviors toward TB in Zhejiang Province, this study indicated that although the GDP and public education level in Zhejiang Province have improved over the past 15 years, the overall rates of discriminatory attitudes and behaviors of the public against TB have not decreased significantly since 2006 and TB discrimination still persists.

In total, nearly $63.5 \%$ of the respondents in the four surveys had a tendency to discriminate against TB patients around them, and the overall prevalence of discriminatory behaviors was $31.2 \%$. The results of the time trend in public discrimination against TB indicated that although there had been a moderating trend in discriminatory attitudes towards TB over the last decade or so, there has been little obvious improvement effect. The rates of TB discriminatory attitudes were still high and discriminatory behaviors had even shown an increasing trend, indicating that the social environment in the fight against TB remains harsh, and reflecting a change in public attitudes towards TB after our health education, but not yet translated into their behaviors, a familiar phenomenon known as "knowdo" gap. ${ }^{19}$ Therefore, routine health education may not be effective in addressing the multiple causes of TB discrimination. More emphasis should be placed on social support for TB patients and deeper health education for the public in the community management of $\mathrm{TB}$, as a more accurate and comprehensive perception of TB in the community will have a positive impact on the ability of the community to provide support to TB patients and on the effectiveness of TB programs. ${ }^{20}$

Our study showed that the elderly, less educated populations and farmers are more likely to have discriminatory attitudes or behaviors toward TB, which is consistent with the findings of other studies. ${ }^{21,22}$ In addition, we analyzed the association between respondents' knowledge of susceptibility and severity of TB and their related attitudes/ behaviors, finding that the categories of TB information and the level of knowledge about TB could affect public attitudes and behaviors toward TB. In fact, the level of community awareness about TB shapes the perceptions of the community about TB and affects health care-seeking behavior, support that patients receive from the household 


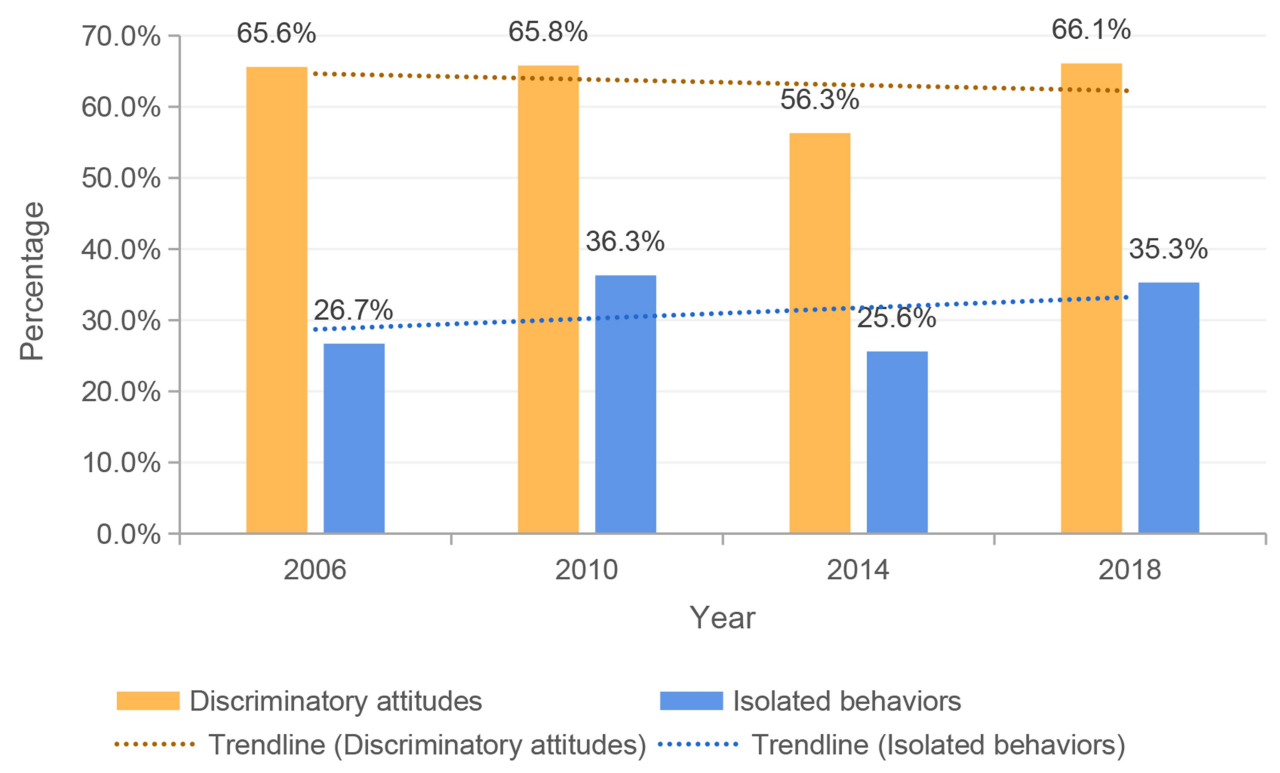

Figure 2 Respondents' discriminatory attitudes and isolated behaviors toward TB and their changing trends across the four surveys from 2006 to 2018 in Zhejiang Province, China.

or community, adherence to treatment, and future engagement in TB prevention and control efforts. ${ }^{23,24}$ For people living with HIV, the relationship between patients' knowledge of their disease and disease-related discrimination has been well documented. ${ }^{25}$ In our study, the high level of discriminatory attitudes among respondents who were aware that TB was infectious and airborne suggests that knowledge of infectiousness or transmission routes alone may not be sufficient to eliminate such attitudes. This suggests that while such knowledge stimulates public awareness of the protection against infectious diseases, it also requires attention to prevent the discriminatory attitudes derived from it. Similarly, members of the public who were aware of someone experiencing coughing and sputum for more than two weeks (suspected to have a TB infection) showed a higher level of isolated behaviors from their surrounding TB patients, which, from a behavioral perspective, could be seen as a manifestation of selfprotective behavior by the public after perceiving the risk of TB. Although it is true that there is a risk of contracting TB when one spends prolonged periods with a TB patient, especially a smear-positive patient, it is worth noting that, generally, two weeks after starting treatment, the patient is no longer infectious. ${ }^{26}$ This is the time when people with TB need care and support from others, deliberate avoidance, and isolated attitudes or behaviors are detrimental to patients' recovery. Although there is a wealth of research discussing the symptoms, modes of transmission, and treatment of TB, few have emphasized how to address discrimination and the stigma attached to this disease. Therefore, the fear of being infected cannot be addressed simply through biomedical knowledge, but requires the implementation of deeper health education and behavioral interventions at schools and in the community, tailored to local contexts and social systems, to raise awareness regarding discrimination. ${ }^{2,10}$

Previous studies reported that patients' knowledge about the curability of TB had an obvious impact on their stigma. ${ }^{27}$ That is, the more one believes that TB is curable, the less stigmatized they are. In our study, respondents who understood the typical symptoms and curability of TB had a lower tendency to have discriminatory attitudes toward TB patients, suggesting that TB curability is a key message to combat the stigma. This reminds us that routine health education materials should not excessively exaggerate the severity of TB and that the clinical manifestations and prognosis of the disease need to be clearly informed to the public.

Although TB patients' psychosocial status is well documented to be affected by stigma and discrimination, little has been done to address this issue. ${ }^{28}$ Multiple causes of discrimination will require multiple interventions to address. Public awareness of TB has improved under the current health education system, but the process of changing from awareness to behavior is still needed. At present, the key knowledge of TB disseminated in various 
Table 5 Multivariate Analysis of the Associated Factors on the Attitude Toward Your Neighbors and Colleagues if They Had TB Among the Respondents Across the Four Surveys from 2006 to 2018 in Zhejiang Province, China

\begin{tabular}{|c|c|c|c|c|}
\hline Variables $^{\mathrm{a}}$ & Discriminatory Attitudes $^{\mathrm{b}}$ (n, \%) & Non-Discriminatory Attitudes ${ }^{c}(n, \%)$ & aOR $(95 \% \mathrm{Cl})$ & $P$ value \\
\hline \multicolumn{5}{|l|}{ Year } \\
\hline 2006 & $3231(65.6)$ & 1697 (34.4) & 1 & \\
\hline 2010 & $3493(65.8)$ & 1817 (34.2) & $1.06(0.97-1.15)$ & 0.221 \\
\hline 2014 & $2853(56.3)$ & $2219(43.7)$ & $0.74(0.67-0.80)$ & $<0.001$ \\
\hline 2018 & $3974(66.1)$ & 2039 (33.9) & $1.08(0.99-1.18)$ & 0.093 \\
\hline \multicolumn{5}{|l|}{ Age in years } \\
\hline $12 \sim 19$ & $322(49.0)$ & $335(51.0)$ & 1 & \\
\hline $20 \sim 29$ & II $63(56.7)$ & $889(43.3)$ & $1.59(1.21-2.07)$ & 0.001 \\
\hline $30 \sim 39$ & $2342(61.2)$ & 1486 (38.8) & $1.65(1.26-2.15)$ & $<0.001$ \\
\hline $40 \sim 49$ & $3543(63.2)$ & $2066(36.8)$ & $1.65(1.27-2.15)$ & $<0.001$ \\
\hline $50 \sim 59$ & $3868(66.5)$ & I95| (33.5) & $1.79(1.38-2.32)$ & $<0.001$ \\
\hline$\geq 60$ & $2310(69.0)$ & $1038(31.0)$ & $1.89(1.44-2.47)$ & $<0.001$ \\
\hline \multicolumn{5}{|l|}{ Educational status } \\
\hline Illiterate & $1733(67.7)$ & $825(32.3)$ & I & \\
\hline Primary School & $4 \mid 22(68.2)$ & $|92|(31.8)$ & $1.02(0.92-1.13)$ & 0.759 \\
\hline Secondary school ${ }^{d}$ & $4808(63.2)$ & $2798(36.8)$ & $0.88(0.79-0.98)$ & 0.021 \\
\hline High school $^{\mathrm{e}}$ & $1687(57.2)$ & $1263(42.8)$ & $0.73(0.64-0.83)$ & $<0.001$ \\
\hline Junior college & $64 I(56.7)$ & $490(43.3)$ & $0.75(0.63-0.90)$ & 0.001 \\
\hline University & $560(54.2)$ & $474(45.8)$ & $0.69(0.57-0.84)$ & $<0.001$ \\
\hline \multicolumn{5}{|l|}{ Occupation } \\
\hline Unemployed & I203 (65.6) & $632(34.4)$ & I & \\
\hline Government staff & $369(56.1)$ & 289 (43.9) & $0.79(0.65-0.97)$ & 0.023 \\
\hline Health care workers & $134(46.7)$ & $153(53.3)$ & $0.53(0.4 I-0.70)$ & $<0.001$ \\
\hline Teachers & $200(57.8)$ & $146(42.2)$ & $0.85(0.66-1.10)$ & 0.222 \\
\hline Professional technicians & 778 (59.9) & $520(40.1)$ & $0.95(0.81-1.12)$ & 0.542 \\
\hline Business/Service personnel & $1330(60.2)$ & $880(39.8)$ & $0.89(0.77-1.01)$ & 0.078 \\
\hline Industrial workers & $1659(58.6)$ & $1170(41.4)$ & $0.79(0.70-0.90)$ & $<0.001$ \\
\hline Farmers & $7422(67.5)$ & 3581 (32.5) & $1.08(0.96-1.20)$ & 0.191 \\
\hline Students & $455(53.2)$ & $40 \mathrm{I}(46.8)$ & $1.07(0.83-1.37)$ & 0.597 \\
\hline \multicolumn{5}{|l|}{ TB is contagious } \\
\hline No/Unknown & $1217(46.0)$ & $1429(54.0)$ & I & \\
\hline Yes & $|2,33|(66.0)$ & $6343(34.0)$ & $1.25(1.12-1.39)$ & $<0.001$ \\
\hline \multicolumn{5}{|c|}{ TB can be transmitted by coughing and sneezing } \\
\hline No/Unknown & $2793(49.2)$ & $2889(50.8)$ & 1 & \\
\hline Yes & $10,757(68.8)$ & $4883(31.2)$ & $2.08(1.91-2.25)$ & $<0.001$ \\
\hline \multicolumn{5}{|c|}{ TB should be suspected if a cough and expectoration persist for more than two weeks } \\
\hline No/Unknown & $9193(64.7)$ & $5020(35.3)$ & 1 & \\
\hline Yes & $4357(61.3)$ & $2750(38.7)$ & $0.84(0.79-0.90)$ & $<0.001$ \\
\hline \multicolumn{5}{|c|}{ What do you think of the severity of TB } \\
\hline Low & $766(45.7)$ & $910(54.3)$ & I & \\
\hline Normal & $6420(62.0)$ & $3939(38.0)$ & $1.77(1.59-1.98)$ & $<0.001$ \\
\hline High & $6364(68.5)$ & $2923(31.5)$ & $2.10(1.88-2.36)$ & $<0.001$ \\
\hline
\end{tabular}


Table 5 (Continued).

\begin{tabular}{|c|c|c|c|c|}
\hline Variables $^{\mathrm{a}}$ & Discriminatory Attitudes $^{\mathrm{b}}(\mathrm{n}, \%)$ & Non-Discriminatory Attitudes ${ }^{c}(n, \%)$ & aOR $(95 \% \mathrm{Cl})$ & $P$ value \\
\hline \multicolumn{5}{|c|}{ If standard treatment is adhered to, most cases of TB can be cured } \\
\hline No/Unknown & $4882(65.5)$ & $2570(34.5)$ & 1 & \\
\hline Yes & $8669(62.5)$ & $5202(37.5)$ & $0.77(0.72-0.82)$ & $<0.001$ \\
\hline
\end{tabular}

Notes: ${ }^{a}$ Variables: variables of sex, residence and marital status were excluded by the logistic stepwise regression; ${ }^{b}$ Discriminatory attitudes: options include not getting along with them anymore and reducing contact with them; ${ }^{c}$ Non-discriminatory attitudes: options include contact them as usual, be more caring and considerate of them; ${ }^{\mathrm{d}} \mathrm{Secondary}$ school: years 13-15; ${ }^{\mathrm{H}} \mathrm{High}$ school: years 16-18.

Abbreviations: aOR, adjusted odds ratio; $\mathrm{Cl}$, confidence interval.

health education programs, as well as the questions included in the surveys, involves symptoms, transmission, treatment, and curability, but does not include any knowledge of social aspects. This indicates that the core knowledge currently transmitted may be insufficient to address the factors that lead to discrimination against people with TB. Therefore, the core information needs to be further refined and modified, and there is an urgent need to integrate biomedical, psychosocial, and economic aspects into our TB health education to address the underlying fears that contribute to the burden of TB. ${ }^{16}$

This study had a few limitations that must be noted. First, due to geographical constraints and considering the economic conditions and low TB prevalence in the

Table 6 Multivariate Analysis of the Associated Factors on the Behaviors Toward the TB Patients Around Among Respondents Across the Four Surveys from 2006 to 2018 in Zhejiang Province, China

\begin{tabular}{|c|c|c|c|c|}
\hline Variables $^{\mathrm{a}}$ & Isolated Behaviors ${ }^{\text {b }}$ (n, \%) & Non-Isolated Behaviors ${ }^{c}(n, \%)$ & Adjusted OR (95\% Cl) & $P$ value \\
\hline \multicolumn{5}{|l|}{ Year } \\
\hline 2006 & $103(26.7)$ & $283(73.3)$ & I & \\
\hline 2010 & $89(36.3)$ & $156(63.7)$ & $1.23(0.77-1.95)$ & 0.382 \\
\hline 2014 & $86(25.6)$ & $250(74.4)$ & $1.07(0.69-1.67)$ & 0.766 \\
\hline 2018 & $195(35.3)$ & $358(64.7)$ & $1.77(1.2 \mathrm{I}-2.58)$ & 0.003 \\
\hline \multicolumn{5}{|l|}{ Occupation } \\
\hline Unemployed & $35(22.4)$ & $121(77.6)$ & 1 & \\
\hline Government staff & $14(28.0)$ & $36(72.0)$ & $0.97(0.40-2.37)$ & 0.952 \\
\hline Health care workers & $7(14.9)$ & $40(85.1)$ & $0.91(0.28-2.96)$ & 0.876 \\
\hline Teachers & $8(28.6)$ & $20(7 \mid .4)$ & $0.75(0.2 \mathrm{I}-2.68)$ & 0.656 \\
\hline Professional technicians & $18(23.7)$ & $58(76.3)$ & $1.33(0.60-2.94)$ & 0.479 \\
\hline Business/Service personnel & $34(24.6)$ & $104(75.4)$ & $1.06(0.55-2.03)$ & 0.866 \\
\hline Industrial workers & $46(23.7)$ & $148(76.3)$ & $1.19(0.65-2.19)$ & 0.572 \\
\hline Farmers & $298(37.9)$ & $489(62.1)$ & $2.43(1.49-3.95)$ & $<0.001$ \\
\hline Students & $13(29.5)$ & $31(70.5)$ & $1.06(0.42-2.68)$ & 0.900 \\
\hline \multicolumn{5}{|l|}{ TB is contagious } \\
\hline No/Unknown & $23(16.2)$ & $119(83.8)$ & 1 & \\
\hline Yes & $450(32.7)$ & $928(67.3)$ & $1.87(1.01-3.46)$ & 0.045 \\
\hline \multicolumn{5}{|c|}{ TB should be suspected if a cough and expectoration persist for more than two weeks } \\
\hline No/Unknown & $247(26.8)$ & $674(73.2)$ & 1 & \\
\hline Yes & $226(37.7)$ & $373(62.3)$ & $1.62(1.20-2.18)$ & 0.002 \\
\hline
\end{tabular}

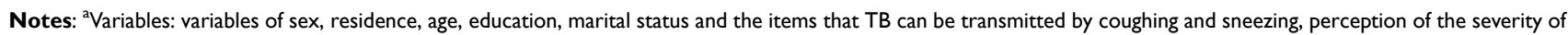
TB, TB can be cured were excluded by the logistic stepwise regression; 'bsolated behaviors: less contact than before; ${ }^{\mathrm{C}} \mathrm{Non}$-isolated behaviors: options include that contacting them as usual, more contact than before.

Abbreviations: Adjusted $\mathrm{OR}$, adjusted odds ratio; $\mathrm{Cl}$, confidence interval. 
Zhejiang Province, the results of our study could be taken to represent southeastern China but may not fully represent the entire nation. Second, the findings we described were from four cross-sectional surveys; thus, the trends in public attitudes and behaviors toward discrimination were affected by the characteristics of the different participants. More prospective studies should be conducted in the future to observe changes in public attitudes and behaviors. Third, inadequate coverage of questions on attitudes and behaviors toward TB in the questionnaire may affect our assessment of the extent of TB discrimination. We suggest that the questionnaire of the knowledge, attitude, and practice toward TB should include more questions related to discrimination and stigma for more comprehensive research.

\section{Conclusion}

In conclusion, despite socio-economic development and the decline of TB prevalence over the previous decade, discriminatory attitudes and isolated behaviors toward TB have not changed significantly in southeastern China, and persistent discrimination against TB still exists. The elderly, less educated populations, farmers tended to have discriminatory attitudes or behaviors toward TB patients. Besides, different levels of knowledge about TB may influence public attitudes and behaviors toward TB. Tailormade strategies, relevant policy measures, and an enabling social environment for TB are urgently required.

\section{Data Sharing Statement}

The datasets used and analyzed during the current study are available from the corresponding author on reasonable request.

\section{Ethics and Consent}

This study was conducted following the principles of Helsinki declarations. The four investigations were approved by the Ethics Committee of the Zhejiang Provincial Centre for Disease Prevention and Control. Each participant was informed about the purpose of the study, its benefits, and confidentiality, and written consent was obtained from every participant in the four surveys prior to their inclusion in the study (eligible individuals who were under the age of 18 were required to obtain the written consent of their guardians). The collected data were kept in a secure way to prevent unauthorized access.

\section{Acknowledgment}

We would like to thank the staff from the local CDCs and the local TB designated hospitals for their help with the field survey.

\section{Author Contributions}

All authors made substantial contributions to conception and design, acquisition of data, or analysis and interpretation of data; took part in drafting the article or revising it critically for important intellectual content; agreed to submit to the current journal; gave final approval of the version to be published; and agree to be accountable for all aspects of the work.

\section{Funding}

This work was supported by the National Natural Science Foundation of China [grant number 71640019]; the Zhejiang Provincial Public Welfare Technology Research Project [grant number LGF19H260004]; Nation-Zhejiang Provincial Health Commission Cooperating Project [grant number WKJ-ZJ-2118]; and the Medical and Health Science and Technology Project of Zhejiang Province [grant number 2020KY095].

\section{Disclosure}

The authors declare no potential conflicts of interest.

\section{References}

1. World Health Organization. Global tuberculosis report; 2020. Available from: https://www.who.int/publications/i/item/ 9789240013131. Accessed November 26, 2020.

2. Baral SC, Karki DK, Newell JN. Causes of stigma and discrimination associated with tuberculosis in Nepal: a Qualitative Study. BMC Public Health. 2007;7(1):211. doi:10.1186/1471-2458-7-211

3. Theron G, Peter J, Zijenah L, et al. Psychological distress and its relationship with non-adherence to TB treatment: a Multicentre Study. BMC Infect Dis. 2015;15(1):253. doi:10.1186/s12879-0150964-2

4. Peltzer K, Pengpid S, Skaal L. Prevalence of psychological distress and associated factors in urban hospital outpatients in South Africa. S Afr J Psychiatry. 2012;18(1):10-15. doi:10.4102/sajpsychiatry. v18i1.304

5. Li Y, Ehiri J, Tang S, et al. Factors associated with patient, and diagnostic delays in Chinese TB patients: a systematic review and meta-analysis. BMC Med. 2013;11(1):156. doi:10.1186/1741-7015$11-156$

6. Xu W, Lu W, Zhou Y, et al. Adherence to anti-tuberculosis treatment among pulmonary tuberculosis patients: a qualitative and quantitative study. BMC Health Serv Res. 2009;9(1):169. doi:10.1186/1472-69639-169

7. Zhang L, Hao C, Wang P, et al. Discussion on ethical issues of protecting the rights of patients in AIDS prevention and control. Chin Med Ethics. 2018;40(6):634-638. In Chinese. 
8. Tadesse S, Kumar A. Stigma against tuberculosis patients in Addis Ababa, Ethiopia. PLoS One. 2016;11(4):e0152900. doi:10.1371/journal.pone.0152900

9. Moya EM, Lusk MW. Tuberculosis stigma and perceptions in the US-Mexico border. Salud Publica Mex. 2013;55(Suppl 4):S498S507. doi:10.21149/spm.v55s4.5155

10. Cremers AL, de Laat MM, Kapata N, et al. Assessing the consequences of stigma for tuberculosis patients in urban Zambia. PLoS One. 2015;10(3):e0119861. doi:10.1371/journal.pone.0119861

11. Abioye IA, Omotayo MO, Alakija W. Socio-demographic determinants of stigma among patients with pulmonary tuberculosis in Lagos, Nigeria. Afr Health Sci. 2011;11(Suppl 1):S100-S104. doi:10.4314/ahs.v11i3.70078

12. Wynne A, Richter S, Jhangri GS, et al. Tuberculosis and human immunodeficiency virus: exploring stigma in a community in western Uganda. AIDS Care. 2014;26(8):940-946. doi:10.1080/ 09540121.2014.882488

13. Chang SH, Cataldo JK. A systematic review of global cultural variations in knowledge, attitudes and health responses to tuberculosis stigma. Int J Tuberc Lung Dis. 2014;18(2):168-173. doi:10.5588/ ijtld.13.0181

14. Datiko DG, Habte D, Jerene D, et al. Knowledge, attitudes, and practices related to TB among the general population of Ethiopia: findings from a national cross-sectional survey. PLoS One. 2019;14 (10):e0224196. doi:10.1371/journal.pone.0224196

15. Macq J, Solis A, Martinez G, et al. Tackling tuberculosis patients' internalized social stigma through patient centred care: an intervention study in rural Nicaragua. BMC Public Health. 2008;8(1):154. doi:10.1186/1471-2458-8-154

16. Sagili KD, Satyanarayana S, Chadha SS, Subbian S. Is knowledge regarding tuberculosis associated with stigmatising and discriminating attitudes of general population towards tuberculosis patients? Findings from a community based survey in 30 districts of India. PLoS One. 2016;11(2):e0147274. doi:10.1371/journal.pone.0147274

17. Qianjiang Evening News. Recent tuberculosis epidemic report of Zhejiang Province; 2019. Available from: https://baijiahao.baidu. com $/ \mathrm{s}$ ?id=1628769194377122449\&wfr=spider \&for=pc. Accessed September 16, 2020.

18. The People's Government of Zhejiang Province. Main data bulletin of 1\% population sampling survey in Zhejiang Province, 2019; 2020. Available from: http://www.zj.gov.cn/art/2020/5/26/art_1544771 43440064.html. accessed September 16, 2020.
19. Sylvia S, Xue H, Zhou C, et al. Tuberculosis detection and the challenges of integrated care in rural China: a Cross-Sectional Standardized Patient Study. PLoS Med. 2017;14(10):e1002405. doi:10.1371/journal.pmed.1002405

20. Juniarti N, Evans D. A qualitative review: the stigma of tuberculosis. $J$ Clin Nurs. 2011;20(13-14):1961-1970. doi:10.1111/j.13652702.2010.03516.x

21. Agho KE, Hall J, Ewald B. Determinants of the knowledge of and attitude towards tuberculosis in Nigeria. $J$ Health Popul Nutr. 2014;32(3):520-538.

22. Yin X, Yan S, Tong Y, et al. Status of tuberculosis-related stigma and associated factors: a cross-sectional study in central China. Trop Med Int Health. 2018;23(2):199-205. doi:10.1111/tmi.13017

23. Fekadu L, Hanson C, Osberg M, et al. Increasing access to tuberculosis services in Ethiopia: findings from a patient-pathway analysis. J Infect Dis. 2017;216(suppl_7):S696-S701. doi:10.1093/infdis/ jix 378

24. Bati J, Legesse M, Medhin G. Community's knowledge, attitudes and practices about tuberculosis in Itang Special District, Gambella Region, South Western Ethiopia. BMC Public Health. 2013;13 (1):734. doi:10.1186/1471-2458-13-734

25. Chung AH, Rimal RN. Revisiting the importance of knowledge: from Namibia, a case for promoting knowledge by campaigns to reduce stigma. Health Educ Behav. 2015;42(2):249-256. doi:10.1177/ 1090198114550824

26. World Health Organization. Treatment of Tuberculosis. Guidelines for National Programmes. 3rd ed. Geneva; 2003.

27. Meulemans H, Mortelmans D, Liefooghe R, et al. The limits to patient compliance with directly observed therapy for tuberculosis: a Socio-Medical Study in Pakistan. Int $J$ Health Plann Manage. 2002;17(3):249-267. doi:10.1002/hpm.675

28. Jaggarajamma K, Ramachandran R, Charles N, et al. Psycho-social dysfunction: perceived and enacted stigma among tuberculosis patients registered under revised national tuberculosis control programme. Indian J Tuberc. 2008;55(4):179-187.
Risk Management and Healthcare Policy

\section{Publish your work in this journal}

Risk Management and Healthcare Policy is an international, peerreviewed, open access journal focusing on all aspects of public health, policy, and preventative measures to promote good health and improve morbidity and mortality in the population. The journal welcomes submitted papers covering original research, basic science, clinical \& epidemiological studies, reviews and evaluations,

\section{Dovepress}

guidelines, expert opinion and commentary, case reports and extended reports. The manuscript management system is completely online and includes a very quick and fair peer-review system, which is all easy to use. Visit http://www.dovepress.com/testimonials.php to read real quotes from published authors. 